\title{
DESCRIZIONE DI UN CASO CLINICO DI MENIGOCOCCEMIA IN UN PAZIENTE IN ETÀ PEDIATRICA.
}

\author{
Ricagni L., Pescetto L., Di Marco E., 'Lattere M., 'Diana MC., \\ Bandettini R.. \\ Laboratorio Analisi Chimico-Cliniche e Microbiologia. \\ 'Pronto Soccorso e Medicina d'Urgenza. \\ Istituto Giannina Gaslini, GENOVA.
}

Introduzione: Neisseria meningitidis colonizza la mucosa rino-faringea e spesso può rendersi responsabile di quadri clinici che variano da batteriemie transitorie a forme severe con coinvolgimento del sistema nervoso.

Caso clinico: Un bambino di 22 mesi, viene ricoverato presso il Pronto Soccorso del nostro Istituto otto ore dopo la comparsa improvvisa di febbre $\left(40^{\circ} \mathrm{C}\right)$ ed un singolo episodio convulsivo. Dall'esame obbiettivo emerge una faringo-tonsillite essudativa e la presenza di 6 maculo-papule sul tronco. Non vengono rilevate alterazioni del sensorio e segni di irritazione meningea. Gli esami ematochimici segnalano solo una leucocitosi $(28000 / \mathrm{mmc})$ con spiccata neutrofilia e una proteina $\mathrm{C}$ reattiva $(\mathrm{PCR})$ negativa. Un successivo episodio convulsivo (3 ore dopo il ricovero) induce il clinico ad eseguire due emocolture (BactAlert - Biomerieux) ed iniziare la terapia antibiotica (ceftriaxone e.v.). Il quadro clinico migliora ed il paziente viene dimesso dopo 24 ore. Al ceftriaxone somministrato per 3 giorni segue il cefuroxime per 10 giorni. Risultati: L'emocoltura si positivizza dopo 15 ore di incubazione e ne risulta un ceppo di Neisseria meningitidis (API $\mathrm{NH}$ - Biomerieux) di gruppo C (Neisseria meningitidis Antiserum - Difco), tipizzazione confermata da Real Time PCR. L'antibiogramma eseguito secondo NCCLS evidenzia la sola resistenza verso la penicillina $(\mathrm{MIC}=0,125 \mu \mathrm{g} / \mathrm{ml}) \mathrm{e}$ la negatività per beta-lattamasi (nitrocefin test - $\mathrm{BD}$ ). Esami ematologici successivi segnalano la leucocitosi e la persistente negatività della PCR.

Discussione: Dalla analisi di questo caso clinico possono emergere alcune riflessioni:

Aspettare la diagnosi microbiologica definitiva prima di iniziare la terapia antibiotica può costituire un rischio per il paziente;

In un soggetto giovane febbrile con convulsioni può essere necessario l'uso di più mezzi diagnostici (batteriologia e biologia molecolare) e in attesa dei risultati deve essere iniziata una terapia antibiotica empirica;

La persistenza della PCR negativa $(<0,46)$ potrebbe essere spiegata con un deficit dell'immunità umorale. 